OPEN ACCESS

Edited by:

Francisco Lopez-Munoz, Camilo José Cela University, Spain

Reviewed by:

Abhijit Nair,

Basavatarakam Indo American Cancer Hospital and Research Institute, India

Zhang Ben Hou,

Capital Medical University, China

${ }^{*}$ Correspondence:

Junli Cao

caoj10310@aliyun.com

Zongwang Zhang

395770436@qq.com

tThese authors have contributed equally to this work.

Specialty section: This article was submitted to

Neuropharmacology, a section of the journal Frontiers in Pharmacology

Received: 12 February 2019 Accepted: 05 July 2019 Published: 02 August 2019

Citation:

Ren C, Gao J, Xu Gj, Xu H, Liu G, Liu L, Zhang L, Cao J-L and Zhang $Z$ (2019) The Nimodipine-Sparing Effect

of Perioperative Dexmedetomidine Infusion During Aneurysmal Subarachnoid Hemorrhage: A Prospective, Randomized, Controlled Trial. Front. Pharmacol. 10:858 doi: 10.3389/fphar.2019.00858

\section{The Nimodipine-Sparing Effect of Perioperative Dexmedetomidine Infusion During Aneurysmal Subarachnoid Hemorrhage: A Prospective, Randomized, Controlled Trial}

\author{
Chunguang Ren ${ }^{1}$, Jian Gao ${ }^{1}$, Guang jun Xu1 ${ }^{1}$, Huiying Xu ${ }^{1}$, Guoying Liu ${ }^{1}$, Lei Liu', \\ Liyong Zhang ${ }^{2}$, Jun-Li Cao ${ }^{3 *+}$ and Zongwang Zhang ${ }^{1 *+}$

\begin{abstract}
Department of Anesthesiology, Liaocheng People's Hospital, Liaocheng, China, ${ }^{2}$ Department of Neurosurgery, Liaocheng
\end{abstract} \\ People's Hospital, Liaocheng, China, ${ }^{3}$ Department of Anesthesiology, Xuzhou Medical University, Xuzhou, China
}

Background: Nimodipine can block the influx of calcium into the vascular smooth muscle cell and prevent secondary ischemia in patients with aneurysmal subarachnoid hemorrhage. However, the reduction of blood pressure after long-term intravenous administration of nimodipine has been associated with neurological deterioration. Yet, no effective solutions have been suggested to address this phenomenon. The use of neuroprotective drug combinations may reduce the risk of sudden blood pressure loss. This prospective, randomized, controlled trial was performed to evaluate the nimodipinesparing effect of perioperative dexmedetomidine infusion during aneurysmal subarachnoid hemorrhage.

Methods: One hundred nine patients who underwent aneurysm embolization were divided into three groups: group C $(n=35$, infused with $0.9 \%$ sodium chloride at the same rate as other two groups), group D1 ( $n=38$, dexmedetomidine infusion at $0.5 \mu \mathrm{g} \cdot \mathrm{kg}^{-1}$ for 10 min, then adjusted to $\left.0.2 \mu \mathrm{g} \cdot \mathrm{kg}^{-1} \cdot \mathrm{h}^{-1}\right)$, and group D2 $(n=36$, dexmedetomidine infusion at $0.5 \mu \mathrm{g} \cdot \mathrm{kg}^{-1}$ for $10 \mathrm{~min}$, then adjusted to $\left.0.4 \mu \mathrm{g} \cdot \mathrm{kg}^{-1} \cdot \mathrm{h}^{-1}\right)$. Patient-controlled analgesia was given for $48 \mathrm{~h}$ after surgery. The primary outcome measure was the total consumption of nimodipine during the first $48 \mathrm{~h}$ after surgery. The secondary outcome measures were recovery time at post-anesthesia care unit (PACU), postoperative pain intensity scores, dexmedetomidine and sufentanil consumption, hemodynamic, satisfaction of patients and neurosurgeon, neurologic examination (Glasgow Coma Scale, GCS), Bruggemann comfort scale, and adverse effects. Intraoperative hemodynamics were recorded at the following time-points: arrival at the operating room (T1); before intubation (T2); intubation (T3); 5 min (T4), 10 min (T5), and 15 min (T6) after intubation; suturing of femoral artery (T7); end of surgery (T8); extubation (T9); and 5 min (T10), 10 min (T11), and 15 min (T12) after arrival at the PACU. The level of sedation was recorded at $15 \mathrm{~min}, 30 \mathrm{~min}, 1 \mathrm{~h}$, and $2 \mathrm{~h}$ after extubation. We also recorded the incidence of symptomatic cerebral vasospasm 
during 7 days after surgery, Glasgow Outcome Score (GOS) at 3 months, and incidence of cerebral infarction 30 days after surgery.

Results: The consumption of nimodipine during the first $48 \mathrm{~h}$ after surgery was significantly lower in group D2 $(P<0.05)$. Compared with group $\mathrm{C}, \mathrm{HR}$ and MAP were significantly decreased from T2 to T12 in group D1 and D2 $(P<0.05)$. Patients in group D2 showed a significantly decreased MAP from T5 to T9 compared with group D1 $(P<0.05)$. The consumption of sevoflurane, remifentanil, dexmedetomidine, and nimodipine were all significantly reduced in groups D1 and D2 during surgery $(P<0.05)$. Compared with group C, MAP was significantly decreased in groups D1 and D2 during the first $48 \mathrm{~h}$ after surgery $(P<0.05)$. Compared with group $\mathrm{C}$, consumption of sufentanil and dexmedetomidine at $1 \mathrm{~h}$, pain intensity at $1 \mathrm{~h}$, and $8 \mathrm{~h}$ after surgery were significantly decreased in groups D1 and D2 $(P<0.05)$. FAS was significantly higher in group D2 at $8 \mathrm{~h}, 16 \mathrm{~h}$, and $24 \mathrm{~h}$ after surgery. LOS was significantly lower only in group D2 at $0.5 \mathrm{~h}$ after surgery $(P<0.05)$. Compared with group $\mathrm{C}$, BCS was significantly higher group D2 at $4 \mathrm{~h}$ and $8 \mathrm{~h}$ after surgery $(P<0.05)$. There were no significant differences among the three groups in consumption of propofol, cisatracurium, fentanyl, and vasoactive drugs during operation, recovery time at PACU, satisfaction of patients and neurosurgeon, and number of applied urapidil and GCS during the first $48 \mathrm{~h}$ after surgery. The incidence of symptomatic cerebral vasospasm during 7 days after surgery, GOS of 3 months, and cerebral infarction after 30 days were also comparable among the three groups.

Conclusions: Dexmedetomidine (infusion at $0.5 \mu \mathrm{g} \cdot \mathrm{kg}^{-1}$ for $10 \mathrm{~min}$, then adjusted to 0.4 $\mu \mathrm{g} \cdot \mathrm{kg}^{-1} \cdot \mathrm{h}^{-1}$ during the surgery) significantly reduced the total consumption of nimodipine during the first $48 \mathrm{~h}$ after surgery and promoted early rehabilitation of patients although the incidences of symptomatic cerebral vasospasm, GOS, and cerebral infarction were not reduced.

Keywords: dexmedetomidine, nimodipine, aneurysmal subarachnoid hemorrhage, aneurysm embolization, cerebral vasospasm

\section{INTRODUCTION}

Aneurysmal subarachnoid hemorrhage (aSAH) is an acute cerebrovascular condition associated with high morbidity and mortality worldwide (Lindgren et al., 2018). It imposes a huge economic burden on public health systems since most patients need long-term care (Wong et al., 2016). According to WHO report, the mortality of patients with aSAH has reduced to $35 \%$. However, complications following aSAH are still a major clinical course (Hughes et al., 2018). One survey shows that up to $45 \%$ of patients with aSAH may have an unfavorable outcome. One of the most important factors associated with poor outcomes is the delayed cerebral infarction (DCI), which usually occurs 3-14 days after aSAH because of prolonged cerebral vasospasm (CVS) (Boulouis et al., 2017). So far, there has been no effective treatment to prevent its occurrence as the mechanism is largely unknown (Shimamura and Ohkuma, 2014).

Previous studies have strongly suggested that nimodipine should be administered via enteral administration except in cases of impaired absorption or metabolism (Soppi et al., 2007; Soppi et al., 2012; Hänggi et al., 2015; Tallarico et al., 2018). However, a major argument for the parenteral route of administration has been proposed as it provides more reliable and stable plasma concentrations (Abboud et al., 2015; Scheller et al., 2016). According to the prevailing evidence, intravenous administration of nimodipine should be used with care as many outcomes such as hypotension may lead to neurological worsening (Ahmed et al., 2000).

Recent studies reported that dexmedetomidine may have a neuroprotective effect and is safe for neurosurgery such as craniotomy and carotid endarterectomy (CEA) (McCutcheon et al., 2006; Garavaglia et al., 2014; Alam et al., 2017; Duan et al., 2018). The general goal of interventional anesthesia in neurosurgery is to keep patients motionless to optimize the quality of images, to maintain hemodynamic stability to avoid the risk of aneurysm rerupture, and to protect the brain against ischemic injury (Prabhakar et al., 2017). Although several studies have shown that hypotension during anesthesia induction may pose harm to the 
patients and increase the risk of early and delayed neurological deficits, general anesthesia is still the first choice (Fan et al., 2017; Ciporen et al., 2018).

Following our search for English language articles published between 1980 and 2017 on MEDLINE, PubMed, Embase, and Cochrane Central Register of Controlled Trials using the terms of dexmedetomidine, nimodipine, aneurysmal subarachnoid hemorrhage, and cerebral vasospasm, we did not find any study on the nimodipine-sparing effect of perioperative dexmedetomidine infusion during aneurysmal subarachnoid hemorrhage. Therefore, we conducted this prospective, randomized, controlled trial on this topic.

\section{MATERIAL AND METHODS}

\section{Patients}

We obtained ethical approval from the Institutional Review Board of Liaocheng People's Hospital to conduct this prospective, randomized, controlled trial. Written informed consent was obtained from patients or their guardian before participation in this trial. The trial was also registered at chictr.org (ChiCTRIPR-16008494, 19/05/2016). All methods were performed in accordance with the relevant guidelines.

Patients admitted to our hospital within $72 \mathrm{~h}$ of initial subarachnoid hemorrhage from October 2016 to June 2018 were included in this trial if they met the following criteria: age 40-75 years, American Society of Anesthesiologists (ASA) grades I to III, diagnosed with aSAH using digital subtraction angiography (DSA), undergoing aneurysm embolization with general anesthesia, using patient-controlled analgesia (PCA) for at least $48 \mathrm{~h}$ after surgery. Patients who met the following criteria were excluded: reoperation within $48 \mathrm{~h}$, taking drugs known to interact with nimodipine such as anticonvulsants within the last month before enrollment, serious systemic diseases of liver and kidney, psychiatric disorders, ischemic heart disease or secondor third-degree atrioventricular block, long-term abuse of alcohol, opioids, or sedative-hypnotic drugs, obesity (body mass index $[\mathrm{BMI}]>30 \mathrm{~kg} / \mathrm{m}^{2}$ ), and operative time $<1 \mathrm{~h}$ or $>3 \mathrm{~h}$.

\section{Randomization and Blinding}

A computer-generated randomization table was used to allocate patients into three groups by an independent anesthetist before surgery: group D1 $(n=38$, dexmedetomidine was infused at $0.5 \mu \mathrm{g} \cdot \mathrm{kg}^{-1}$ for $10 \mathrm{~min}$, then adjusted to $\left.0.2 \mu \mathrm{g} \cdot \mathrm{kg}^{-1} \cdot \mathrm{h}^{-1}\right)$, group D2 ( $n=36$, dexmedetomidine was infused at $0.5 \mu \mathrm{g} \cdot \mathrm{kg}^{-1}$ for $10 \mathrm{~min}$, then adjusted to $\left.0.4 \mu \mathrm{g} \cdot \mathrm{kg}^{-1} \cdot \mathrm{h}^{-1}\right)$, and group $\mathrm{C}(n=35,0.9 \%$ sodium chloride was infused at rate the same as the other two groups). A team of nurses who offered the Acute Pain Services were blinded to this trial, and they prepared the experimental drug (dexmedetomidine was diluted to $50 \mathrm{ml}$ using $0.9 \%$ sodium chloride in groups D1 and D2) and the PCA pump (sufentanil $\left(0.01 \mu \mathrm{g} \cdot \mathrm{kg}^{-1} \cdot \mathrm{h}^{-1}\right)$ plus dexmedetomidine $\left(0.1 \mu \mathrm{g} \cdot \mathrm{kg}^{-1} \cdot \mathrm{h}^{-1}\right)$ programmed to deliver a bolus of $2 \mathrm{ml}$, with a background infusion of $2 \mathrm{ml} \cdot \mathrm{h}^{-1}$, a lockout of $5 \mathrm{~min}$, and 1-h limit of $16 \mathrm{ml}$ ). All anesthesiologists and neurosurgeons who participated in this trial were blinded.

\section{Anesthesia}

All patients had not been premedicated. Peripheral venous was established in the left upper extremity before the start of anesthesia, then five-lead electrocardiogram, noninvasive blood pressure, oxygen saturation, temperature, and bispectral index (Aspect Medical System, Newton, MA, USA) were continuously monitored using an automated system (IntelliVue MP50, Philips, Amsterdam, the Netherlands). The anesthetic methods adopted are routinely used in our center (Su et al., 2016). Oxygen (100\%) was administered via a facial mask at $4 \mathrm{~L} / \mathrm{min}$ for $5 \mathrm{~min}$. After the experimental drug $(0.9 \%$ sodium chloride in group $\mathrm{C}$ or dexmedetomidine in groups D1 and D2) was infused for $10 \mathrm{~min}$ in three groups, fentanil $\left(2-3 \mu \mathrm{g} \cdot \mathrm{kg}^{-1}\right)$, propofol $(1.5-2$ $\left.\mathrm{mg} \cdot \mathrm{kg}^{-1}\right)$, and cisatracurium $\left(0.2 \mathrm{mg} \cdot \mathrm{kg}^{-1}\right)$ were administered intravenously, and tracheal intubation was performed $3 \mathrm{~min}$ later. Sevoflurane $(1.5-2.1 \%)$, remifentanil $\left(0.05-0.1 \mu \mathrm{g} \cdot \mathrm{kg}^{-1} \cdot \mathrm{min}^{-1}\right)$, and nimodipine $\left(5-20 \mu \mathrm{g} \cdot \mathrm{kg}^{-1} \cdot \mathrm{h}^{-1}\right)$ were administered during surgery. Cisatracurium $\left(0.05 \mathrm{mg} \cdot \mathrm{kg}^{-1}\right)$ was intermittently added to maintain muscle relaxation. The pressure of arterial carbon dioxide $\left(\mathrm{PaCO}_{2}\right)$ was maintained at $35-40 \mathrm{mmHg}$ during surgery. Sevoflurane and the experimental drugs were stopped when all of the coils were placed. Remifentanil was continued until the femoral artery was sutured. All patients received $5 \mathrm{mg}$ of tropisetron and underwent routine reversal of neuromuscular blockade (atropine $4 \mu \mathrm{g} \cdot \mathrm{kg}^{-1}$ plus neostigmine $15 \mu \mathrm{g} \cdot \mathrm{kg}^{-1}$ ) at the end of surgery.

The concentration of sevoflurane was adjusted by $0.2 \%$ stepwise titration according to BIS. Remifentanil infusion was adjusted by $0.01-\mu \mathrm{g} \cdot \mathrm{kg}^{-1} \cdot \mathrm{min}^{-1}$ stepwise titration according to acceptable hemodynamic limits. Nimodipine was adjusted by $5-\mu \mathrm{g} \cdot \mathrm{kg}^{-1} \cdot \mathrm{h}^{-1}$ stepwise titration if premise of satisfactory depth of anesthesia and poor response to remifentanil. Besides, phenylephrine, ephedrine, atropine, and urapidil were used where necessary. Endovascular embolization was performed by the same neurosurgeon who had more than 15 years of residency experience.

\section{Postoperative Management}

All patients underwent head computed tomography (CT) scan immediately after surgery to detect acute complications such as hemorrhage before they were transferred to the PACU. The same neurosurgeon performed neurological examination and trained the patients to operate the PCA pump. Patients were encouraged to push the bolus of PCA when VASm $>3$. For patients with poor response to PCA, $1 \mathrm{mg}$ butorphanol was administered intravenously.

Nimodipine was infused at $5-20 \mu \mathrm{g} \cdot \mathrm{kg}^{-1} \cdot \mathrm{h}^{-1}$ to maintain hemodynamic parameters after surgery according to the standards of "Guidelines for the Management of Aneurysmal Subarachnoid Hemorrhage: A Guideline for Healthcare Professionals from the American Heart Association/American Stroke Association" (Lawton and Vates, 2017). The following interventions were performed if patients showed neurological symptoms in the postoperative period: positive concordance between clinical examination and transcranial Doppler ultrasound (TCD) results led to induction of hypertensive therapy, and discordance 
between clinical examination and TCD results led to further testing with CT or computed tomography angiography (CTA) (Jung et al., 2012). All patients received CTA as a routine examination at discharge.

\section{Data Collection}

The primary outcome measure was the total consumption of nimodipine during the first $48 \mathrm{~h}$ after surgery. The secondary outcome measures were recovery time at PACU, the movement of postoperative pain intensity score (VASm), consumption of dexmedetomidine and sufentanil, hemodynamic satisfaction of patients and neurosurgeon, neurological examination (Glasgow coma scale, GCS), Bruggemann comfort scale (BCS: 0 , persistent pain; 1 , severe pain while deep breathing or coughing; 2, mild pain while deep breathing or coughing; 3 , no pain while deep breathing; and 4, no pain while coughing) and adverse effects.

Intraoperative hemodynamic data (MAP and HR) were recorded at the following time-points: arrival at the operating room (T1); before intubation (T2); intubation (T3); 5 min (T4), $10 \mathrm{~min}$ (T5), and $15 \mathrm{~min}$ (T6) after intubation; suturing of femoral artery (T7); end of surgery (T8); extubation (T9); and $5 \mathrm{~min}$ (T10), $10 \mathrm{~min}$ (T11), $15 \mathrm{~min}$ (T12) after arrival at the PACU. Level of sedation (LOS: 0 , fully awake; 1 , drowsy/closed eyes; 2, asleep/easily aroused with light tactile stimulation or a simple verbal command; 3 , asleep/arousable only by strong physical stimulation; and 4, unarousable) was recorded at $15 \mathrm{~min}$ and $30 \mathrm{~min}$ and $1 \mathrm{~h}$ and $2 \mathrm{~h}$ after extubation. We also recorded the incidence of symptomatic cerebral vasospasm during 7 days after surgery, Glasgow Outcome Score (GOS) at 3 months, and incidence of cerebral infarction 30 days after surgery.

\section{Statistical Analyses}

According to our previous study, the sample size was calculated on the basis of an expected difference of $20 \%$ in the cumulative amount of nimodipine utilized $48 \mathrm{~h}$ after surgery. For a study power of $80 \%(\alpha=0.05, \beta=0.2)$, the required sample size per group was calculated to be 32 (PASS 11.0, NCSS Statistical Software, Kaysville, Utah). Assuming a dropout rate of $10 \%$, the final sample size was determined to be 35 patients for each group.

Statistical analyses were carried out using SPSS for Windows Version 21.0 (SPSS Inc. Chicago, IL, USA). The Kolmogorov-Smirnov test was used to assess the distribution of the variables. Homogeneity of variance was determined using Levene's test. Normally distributed continuous variables were presented as mean $\pm \mathrm{SD}$. Inter-group comparisons were performed using repeated-measures analysis of variance. The Bonferroni's correction was used for post hoc multiple comparisons. The nonparametric Kruskal-Wallis test was used for non-normally distributed continuous variables presented as an inter-quartile range. Categorical data were expressed as frequencies and percentages and analyzed using chi-squared tests or Fisher's exact tests. $P<0.05$ was considered statistically significant.

\section{RESULTS}

\section{Baseline Characteristics}

A CONSORT diagram was used during the enrollment of patients (Figure 1). One hundred seventy-nine patients who underwent aneurysm embolization from October 2016 to June 2018 were recruited. Fifty-nine patients were excluded: ASA of 12 patients >III; five patients had anticonvulsants in the last month; four patients had serious systemic diseases of kidney; four patients had psychiatric disorders; six patients had ischemic heart disease or second- or third-degree atrioventricular block; 16 patients had long-term abuse of alcohol, opioids, or sedativehypnotic drugs; BMI of six patients $>30 \mathrm{~kg} / \mathrm{m}^{2}$; and six patients had an operative time $>3 \mathrm{~h}$. Finally, 120 patients were included in the primary analysis, among whom 11 were excluded (five patients from group C, two patients from group D1, and four patients from group D2). At last, 109 remaining patients were divided into three groups: 35 patients for group C, 38 patients for group D1, and 36 patients for group D2. Three groups were comparable in terms of age, BMI, ASA grade, sex, comorbidity, and GCS before surgery $(P>0.05)$ (Table 1).

\section{Intraoperative Variables}

$\mathrm{HR}$ and MAP were not significantly different among the three groups at arrival in the operating room $(P>0.05)$. Compared with group $\mathrm{C}$, patients in groups D1 and D2 showed significantly decreased HR and MAP from T2 to T12 $(P<0.05)$. Patients in group D2 showed a significant decrease in MAP from T5 to T9 compared with group D1 $(P<0.05)$ (Figure 2).

Compared with group $\mathrm{C}$, consumption of sevoflurane (1.70[1.50-1.70] vs. $1.50[1.50-1.70]$ vs. $1.50[1.50-1.50] \%$, $P=0.007)$, remifentanil $(628.24 \pm 76.42$ vs. $523.37 \pm 73.66$ vs. $453.37 \pm 86.11 \mu \mathrm{g}, P<0.001)$, dexmedetomidine (0 vs. 61.74 [57.33-66.29] vs. 87.89 [81.37-95.72] $\mu g, P<0.001)$, and nimodipine ( $1.42 \pm 0.17$ vs. $1.13 \pm 0.13$ vs. $0.69 \pm 0.20 \mathrm{mg}, P<$ 0.001 ) were significantly reduced in groups D1 and D2-these differences were also statistically significant between groups D1 and D2 (Table 2). There were no significant differences among the three groups in the duration of surgery and anesthesia, consumption of propofol, cisatracurium, and fentanyl $(P>0.05)$ (Table 2). The number of patients using atropine, ephedrine, phenylephrine, and urapidil was comparable among the three groups during operation (Table 3 ).

\section{Postoperative Variables}

The consumption of nimodipine during the first $48 \mathrm{~h}$ after surgery was significantly lower in group D2 (63.36 [60.48-69.12] vs. 51.84 [48.38-55.30] vs. $31.92[30.24-34.44] \mathrm{mg}, P<0.001)$ (Table 4). Compared with group C, HR at $1 \mathrm{~h}$ after surgery was significantly decreased in groups D1 and D2 $(P<0.05)$, while MAP was significantly decreased in groups D1 and D2 during the first $48 \mathrm{~h}$ after surgery $(P<0.05)$ (Figure 3$)$. FAS was significantly higher in group D2 at $8 \mathrm{~h}(P=0.021), 16 \mathrm{~h}(P=$ $0.007)$, and $24 \mathrm{~h}(P=0.001)$ after surgery (Table 5).

Compared with group $\mathrm{C}$, consumption of sufentanil and dexmedetomidine at $1 \mathrm{~h}$ after surgery was significantly 


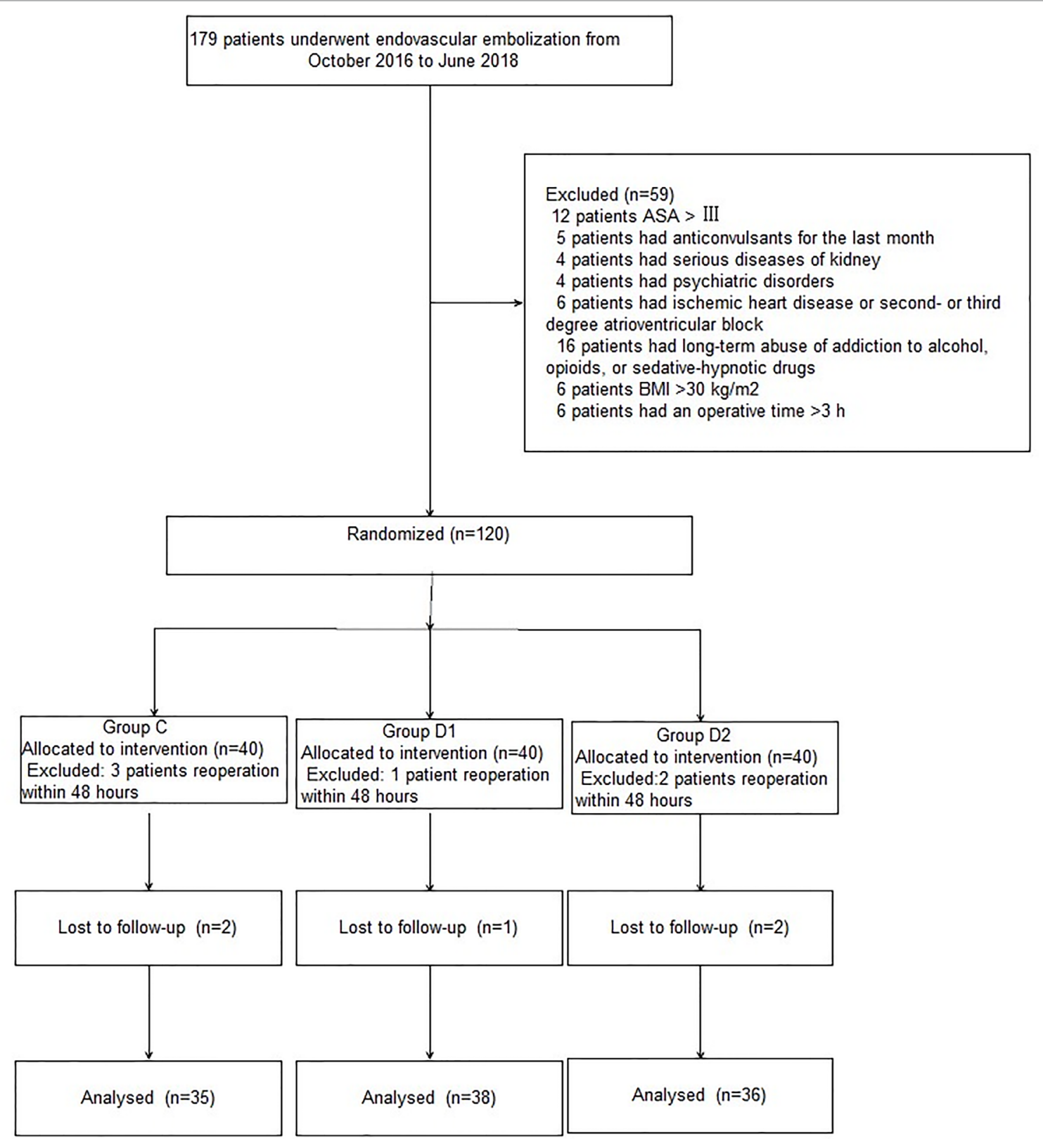

FIGURE 1 | Patients enrollment flow diagram.

decreased in groups D1 and D2 $(P<0.05)$ (Figure 4). Compared with group $\mathrm{C}$, the pain intensity was only significantly lower at $1 \mathrm{~h}$ and $8 \mathrm{~h}$ after surgery $(P<0.05)$ (Figure 5). LOS was significantly lower only in group D2 at $0.5 \mathrm{~h}$ after surgery $(P<$ 0.05 ) (Figure 6). Compared with group C, BCS was significantly higher in group D2 at $4 \mathrm{~h}$ and $8 \mathrm{~h}$ after surgery $(P<0.05)$ (Figure 7). There were no significant differences among the three groups in recovery time at PACU, satisfaction of patients and neurosurgeon, number of patients given urapidil, and GCS during first $48 \mathrm{~h}$ after surgery $(P>0.05)$ (Table 4, Figure 8). The incidence of symptomatic cerebral vasospasm during 7 days after surgery, GOS at 3 months, and cerebral infarction after 30 days were comparable among the three groups (Table 4). Additionally, there were no significant differences among the three groups in adverse effects such as nausea, dizziness, thirst, hypotension, and hypertension (Table 6).

\section{DISCUSSION}

We report, for the first time, that high dose of dexmedetomidine (infusion at $0.5 \mu \mathrm{g} \cdot \mathrm{kg}^{-1}$ for $10 \mathrm{~min}$, then adjusted to $0.4 \mu \mathrm{g} \cdot \mathrm{kg}^{-1} \cdot \mathrm{h}^{-1}$ during the surgery) significantly reduced the total consumption of nimodipine during the first $48 \mathrm{~h}$ after surgery without any 
TABLE 1 | Clinical characteristics of patients in the three groups.

\begin{tabular}{|c|c|c|c|c|}
\hline Variable & Group C $(n=35)$ & Group D1 $(n=38)$ & Group D2 $(n=36)$ & $P$-values \\
\hline Age (years) & $62.11 \pm 5.87$ & $61.79 \pm 6.28$ & $62.20 \pm 7.54$ & .962 \\
\hline Body weight (kg) & $67.29 \pm 6.39$ & $67.55 \pm 5.73$ & $66.81 \pm 7.86$ & .890 \\
\hline $\mathrm{BMI}\left(\mathrm{kg} \cdot \mathrm{m}^{-2}\right)$ & $23.91 \pm 2.05$ & $24.08 \pm 2.25$ & $23.44 \pm 2.27$ & .441 \\
\hline ASA I/II/III (n) & $5 / 21 / 9$ & $6 / 26 / 6$ & $7 / 22 / 7$ & .835 \\
\hline Sex (male/female) & $17 / 18$ & $19 / 19$ & $21 / 15$ & .678 \\
\hline Comorbidity, $n$ (\%) & & & & .995 \\
\hline Hypertension & 17 (48.57\%) & $21(55.26 \%)$ & 14 (38.89\%) & \\
\hline Diabetes mellitus & $6(17.14 \%)$ & 7 (18.42\%) & $6(16.67 \%)$ & \\
\hline Coronary heart disease & $3(8.57 \%)$ & $4(10.53 \%)$ & $3(8.33 \%)$ & \\
\hline GCS before surgery & $15.00(14.00-15.00)$ & $15.00(14.00-15.00)$ & $14.00(14.00-15.00)$ & .685 \\
\hline
\end{tabular}

Variables presented as mean $\pm S D$, median (interquartile range) or number of patients n (\%). BMI, body mass index; ASA, American Society of Anesthesiology; GCS, Glasgow Coma Scale.

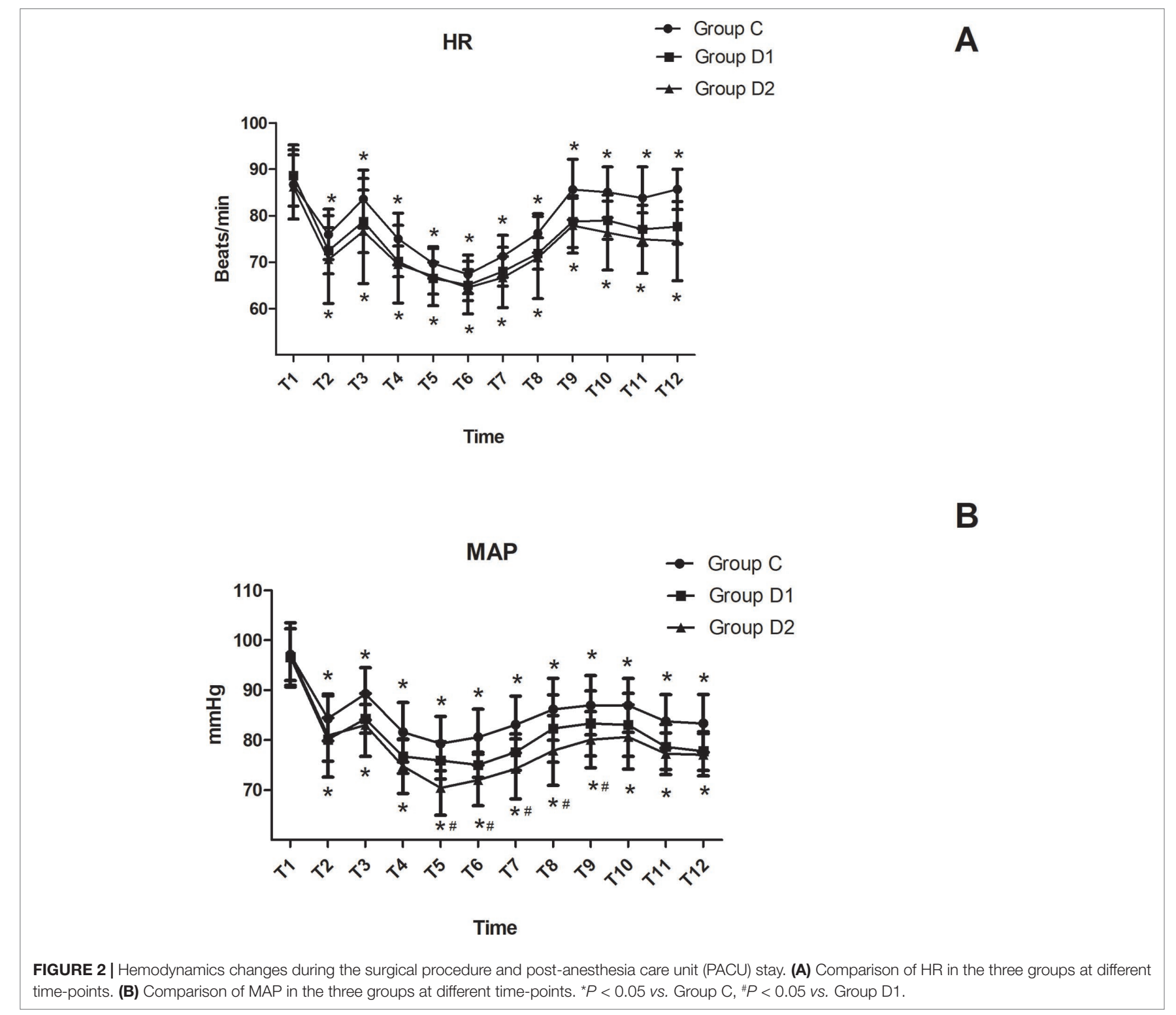

related complications. We also found that the requirements of sevoflurane, remifentanil, and nimodipine in group D2 were significantly decreased during the operation. Although more patients in group $\mathrm{C}$ needed vasoactive drugs during the first $48 \mathrm{~h}$ after surgery, there was no significant difference among the three groups. Compared with group C, FAS at 8-24 h, BCS at $4-8 \mathrm{~h}$, pain intensity at $1 \mathrm{~h}$, and $8 \mathrm{~h}$ after surgery were significantly improved in group D2. LOS in group D2 was significantly lower 
TABLE 2 | Comparison of intraoperative variables in the three groups.

\begin{tabular}{|c|c|c|c|c|}
\hline Variable & Group C $(n=35)$ & Group D1 $(n=38)$ & Group D2 $(n=36)$ & $P$-values \\
\hline Duration of surgery (min) & $113.00(105.00-121.00)$ & 110.00 (102.00-119.25) & 110.50 (102.50-122.75) & .770 \\
\hline Duration of anesthesia (min) & 135.00 (125.00-146.00) & 130.50 (126.00-140.50) & $134.50(127.25-147.50)$ & .694 \\
\hline Remifentanil dosage $(\mu \mathrm{g})$ & $628.24 \pm 76.42$ & $523.37 \pm 73.66^{\star}$ & $453.37 \pm 86.11^{\star \#}$ & .000 \\
\hline Dexmedetomidine dosage $(\mu \mathrm{g})$ & - & $61.74(57.33-66.29)^{\star}$ & $87.89(81.37-95.72)^{\star \#}$ & .000 \\
\hline Nimodipine dosage (mg) & $1.42 \pm 0.17$ & $1.13 \pm 0.13^{\star}$ & $0.69 \pm 0.20^{\star \#}$ & .000 \\
\hline Propofol dosage (mg) & 120.00 (110.00-130.00) & 120.00 (110.00-140.00) & 120.00 (110.00-147.50) & .697 \\
\hline Cisatracurium dosage (mg) & $19.03 \pm 3.71$ & $19.42 \pm 3.54$ & $19.00 \pm 3.93$ & .862 \\
\hline Fentanyl dosage (mg) & $0.20(0.20-0.25)$ & $0.20(0.20-025)$ & $0.20(0.20-0.20)$ & .233 \\
\hline Sevoflurane (\%) & $1.70(1.50-1.70)$ & $1.50(1.50-1.70)^{\star}$ & $1.50(1.50-1.50)^{\star \#}$ & .007 \\
\hline
\end{tabular}

Variables presented as mean $\pm S D$ or median (interquartile range). ${ }^{*} P<0.05$ vs. Group $C,{ }^{*} P<0.05$ vs. Group D1.

TABLE 3 | Consumption of vasoactive drugs during operation.

\begin{tabular}{|c|c|c|c|c|}
\hline Variable & Group C $(n=35)$ & Group D1 $(n=38)$ & Group D2 $(n=36)$ & $P$-values \\
\hline Atropine & 2 (5.71\%) & 3 (7.89\%) & 7 (19.44\%) & .196 \\
\hline Ephedrine & $3(8.57 \%)$ & $6(15.79 \%)$ & 6 (16.67\%) & .607 \\
\hline Phenylephrine & 5 (14.29\%) & 5 (13.16\%) & $3(8.33 \%)$ & .758 \\
\hline Urapidil & $4(11.43 \%)$ & $4(10.53 \%)$ & 2 (5.56\%) & .708 \\
\hline
\end{tabular}

Variables presented as number of patients $n$ (\%).

TABLE 4 | Consumption of postoperative variables in the three groups.

\begin{tabular}{|c|c|c|c|c|}
\hline Variable & Group C $(n=35)$ & Group D1 $(n=38)$ & Group D2 $(n=36)$ & $P$-values \\
\hline Recovery time at PACU (min) & $16.00(13.00-18.00)$ & $15.00(12.75-17.00)$ & $15.00(12.00-19.00)$ & .862 \\
\hline Nimodipine dosage (mg) & $63.36(60.48-69.12)$ & $51.84(48.38-55.30)^{\star}$ & $31.92(30.24-34.44)^{\star \#}$ & .000 \\
\hline Patient satisfaction score & $8.00(8.00-9.00)$ & $8.00(8.00-9.00)$ & $9.00(8.00-9.00)$ & .055 \\
\hline Neurosurgeon satisfaction score & $9.00(8.00-9.00)$ & $9.00(8.00-9.00)$ & $9.00(8.00-9.00)$ & .996 \\
\hline Symptomatic cerebral vasospasm & $2(5.71 \%)$ & $2(5.26 \%)$ & $2(5.56 \%)$ & 1.000 \\
\hline Number of applied urapidil, $n(\%)$ & $9(25.71 \%)$ & $7(18.42 \%)$ & $4(11.11 \%)$ & .288 \\
\hline GOS of 3 months $(3 / 4 / 5)$ & $4 / 13 / 18$ & $2 / 13 / 23$ & $3 / 15 / 18$ & .815 \\
\hline Cerebral infarction after $30 \mathrm{~d}, n(\%)$ & $8(22.86 \%)$ & $7(18.42 \%)$ & $5(13.89 \%)$ & .642 \\
\hline
\end{tabular}

Variables presented as median (interquartile range) or number of patients $n$ (\%). PACU, post-anesthesia care unit; GOS, Glasgow outcome scale. ${ }^{*} P<0.05$ vs. Group $C$, ${ }^{\sharp} P<0.05$ vs. Group D1.

at $0.5 \mathrm{~h}$ after surgery, which may be attributed to the lower consumption of sufentanil and dexmedetomidine. We found no significant differences among the three groups in recovery time at PACU, the satisfaction of patients and surgeon, GCS, the incidence of symptomatic cerebral vasospasm during 7 days after surgery, GOS at 3 months, and cerebral infarction after 30 days.

Statistically, aSAH accounts for about $5 \%$ of all strokes patients. The suspected high-risk factors include hypertension, smoking, alcohol abuse, the use of sympathomimetic drugs, being female, unruptured cerebral aneurysm, a history of previous aSAH, and familial aneurysms (Tallarico et al., 2018). Mortality due to this condition was remarkably reduced from 1970 to 1990 due to the development of new diagnostics and treatments (Kellner et al., 2012). Although treatment of high blood pressure with antihypertensive medication is recommended by AHA and ASA at the level of evidence A to prevent serious complications, only oral nimodipine is recommended for all patients with aSAH to improve neurological outcomes (Connolly et al., 2012). In our center, aSAH patients are routinely admitted to the neurosurgery intensive care unit (NICU) and managed by a multidisciplinary team. They are regularly treated with intravenous infusion of nimodipine at $1-2 \mathrm{mg} \cdot \mathrm{h}^{-1}$ or enteral administration of $60 \mathrm{mg}$ orally at $4 \mathrm{~h}$ intervals. If the systolic blood pressure $<110 \mathrm{~mm} \mathrm{Hg}$, the infusion rate of nimodipine is reduced to $0.5-1 \mathrm{mg} \cdot \mathrm{h}^{-1}$ according to previous studies. The consumption of nimodipine during the first $48 \mathrm{~h}$ after surgery was lower than previous studies, possibly due to the use of different drug combinations (Zarauza et al., 2000; Casey et al., 2006).

$33.7 \%$ of patients with SAH have an unfavorable outcome because of cerebral vasospasm caused by an increase of calcium level in the vascular smooth muscle cells. However, the percentage of patients with unfavorable outcome has been underestimated in many studies due to the exclusion of patients who die before treatment (Konczalla et al., 2016). Here, we only recorded the incidence of symptomatic cerebral vasospasm 7 days after surgery since the highest risk period for cerebral vasospasm usually occurs 3-14 days after aSAH and the duration of discharge after surgery was within 8 days for most patients in our center (Oertel et al., 2005). The commonly used methods to monitor cerebral vasospasm include clinical, physiological, and radiographic. Clinical examination is generally thought to be suitable for good-grade patients. Physiological monitoring 

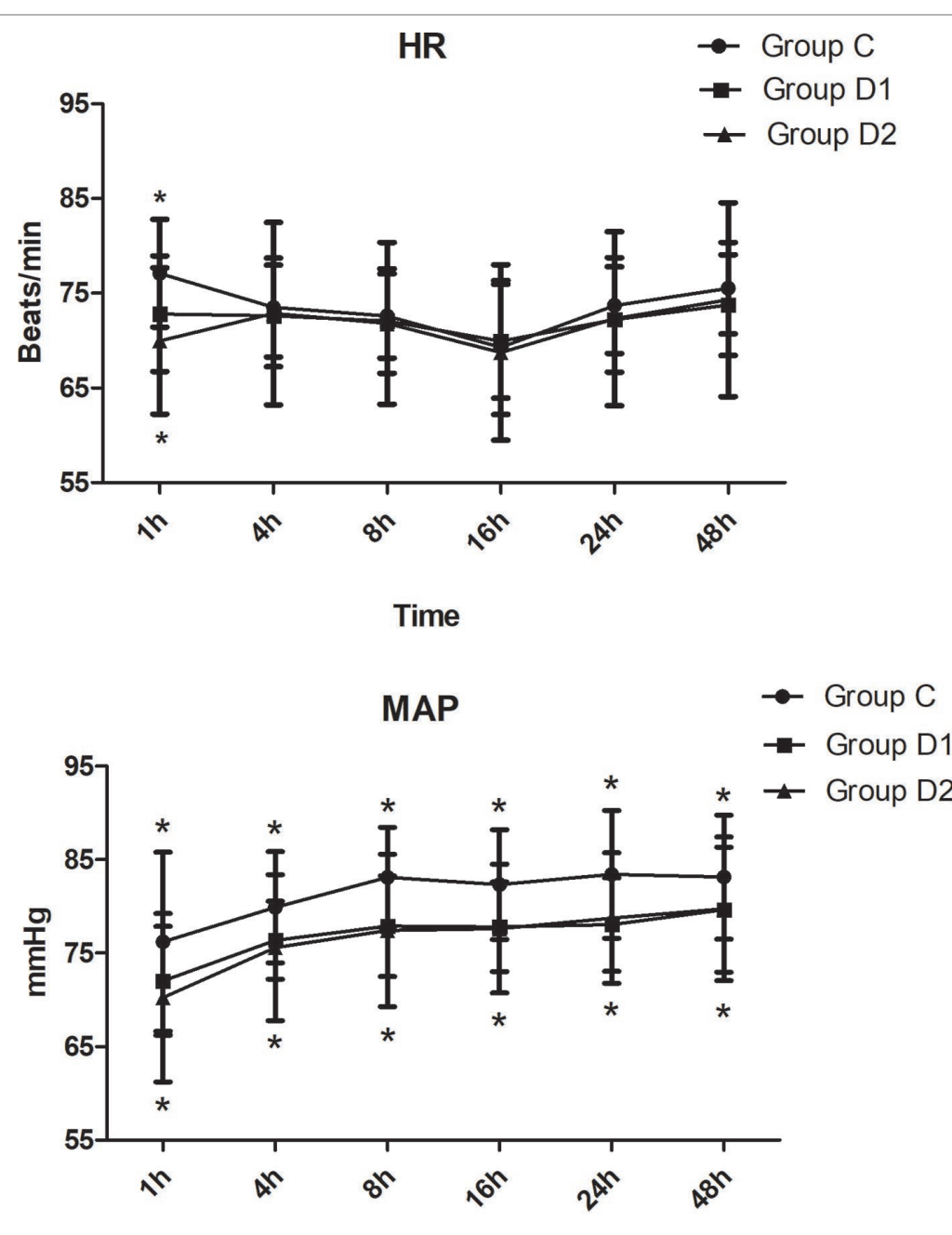

Time

FIGURE 3 | Hemodynamics changes during the first $48 \mathrm{~h}$ after surgery. (A) Comparison of HR in the three groups at different time-points. (B) Comparison of MAP in the three groups at different time-points. ${ }^{*} P<0.05$ vs. Group C.

TABLE 5 | FAS during $48 \mathrm{~h}$ after surgery in the three groups.

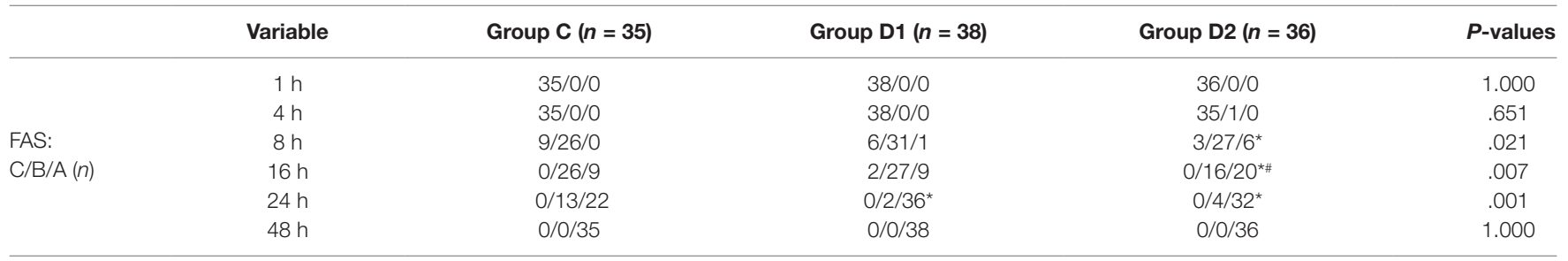

Variables presented as number of patients $n$. FAS, functional activity score. ${ }^{*} P<0.05$ vs. Group $C,{ }^{\sharp} P<0.05$ vs. Group $D 1$.

includes transcranial TCD, electroencephalography (EEG), brain tissue oxygen monitoring, cerebral microdialysis, thermal diffusion cerebral blood flow (TD-CBF), and near-infrared spectroscopy. Additionally, DSA, CTA/CTP, CTA-MMBE (CTA combined with matched mask bone elimination), and dual-energy CTA are the common radiographic examinations (Bacigaluppi et al., 2015; Rao and Muthuchellappan, 2016). Sanelli et al. suggested that CTA and CTP are the preferred imaging strategy than TCD in aSAH as they improve the clinical outcomes and lower health care costs. However, DSA is still the gold standard for diagnosing cerebral vasospasm although it carries some risk of vascular complications such as thromboembolism and dissection (Sanelli et al., 2014). Similar to a previous study, we first performed clinical examination before further monitoring in this trial to reduce medical costs (Bricout et al., 2015). As a result, we only recruited patients of ASA I 


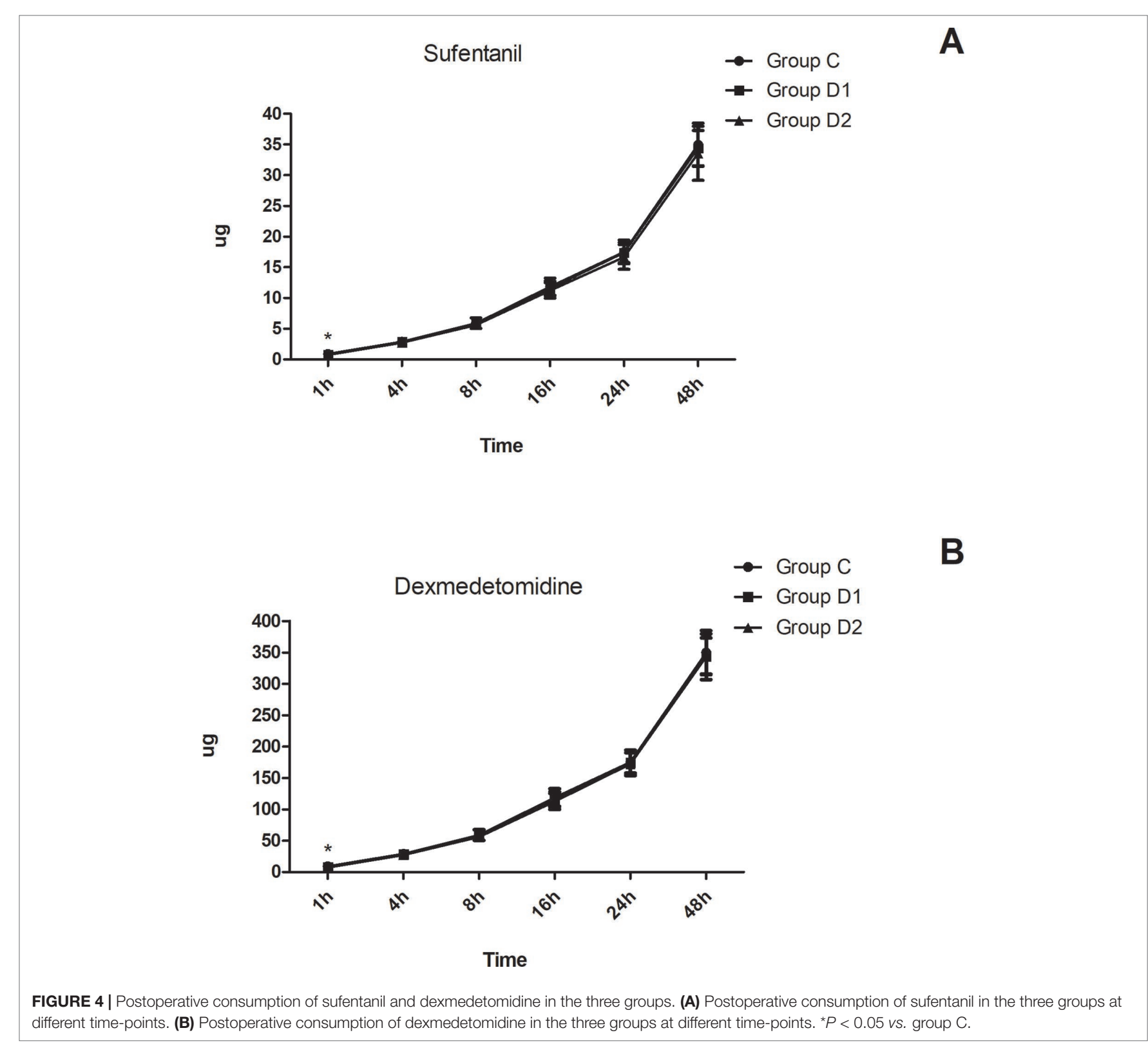

\section{A}

to III. However, previous studies recommend that radiographic and/or physiological monitoring should be routinely performed for SAH patients during "at risk" period even in the absence of clinical evidence of DCI. This may explain the lower incidence of symptomatic cerebral vasospasm observed 7 days after surgery in this study (Francoeur and Mayer, 2016). In our trial, we also evaluated the occurrence of cerebral infarction 30 days after surgery with TCD or CT/CTA and the incidence was similar to that of a previous study (Chhor et al., 2011).

Previous studies have proposed the use of calcium channels blockers to prevent secondary ischemia as these drugs can suppress the influx of calcium into the vascular smooth muscle cell, thereby decreasing the rate of vasospasm (Tjahjadi et al., 2013). Systematic reviews found that endovascular treatments such as intra-arterial injection of pharmacological agents e.g., nimodipine or papaverine and balloon angioplasty, may improve the outcome of patients with severe-refractory vasospasm (Zwienenberg-Lee et al., 2008; Kieninger et al., 2018). Contrary to this conclusion, a previous study showed that nimodipine administration, specifically by intra-arterial bolus application, is associated with a reduction in MAP and CPP, which will require high doses of vasopressors to maintain cerebral perfusion. In addition, phlebitis at the injection site and pulmonary edema in addition to azotemia may occur as complications (Adami et al., 2019). Unfortunately, we did not record these complications in our trial for the lack of human and financial resources.

$\mathrm{Niaz}$ et al. found that the reduction of diastolic pressure ( $>20 \%$ reduction) was associated with neurological worsening after intravenous administration of $2 \mathrm{mg} \cdot \mathrm{h}^{-1}$ nimodipine within $24 \mathrm{~h}$ after acute stroke, partly because of the higher incidence of cardiac ischemia. As a result, intravenous high-dose nimodipine $\left(2 \mathrm{mg} \cdot \mathrm{h}^{-1}\right)$ seemed to be outweighed by the hemodynamic effect. 


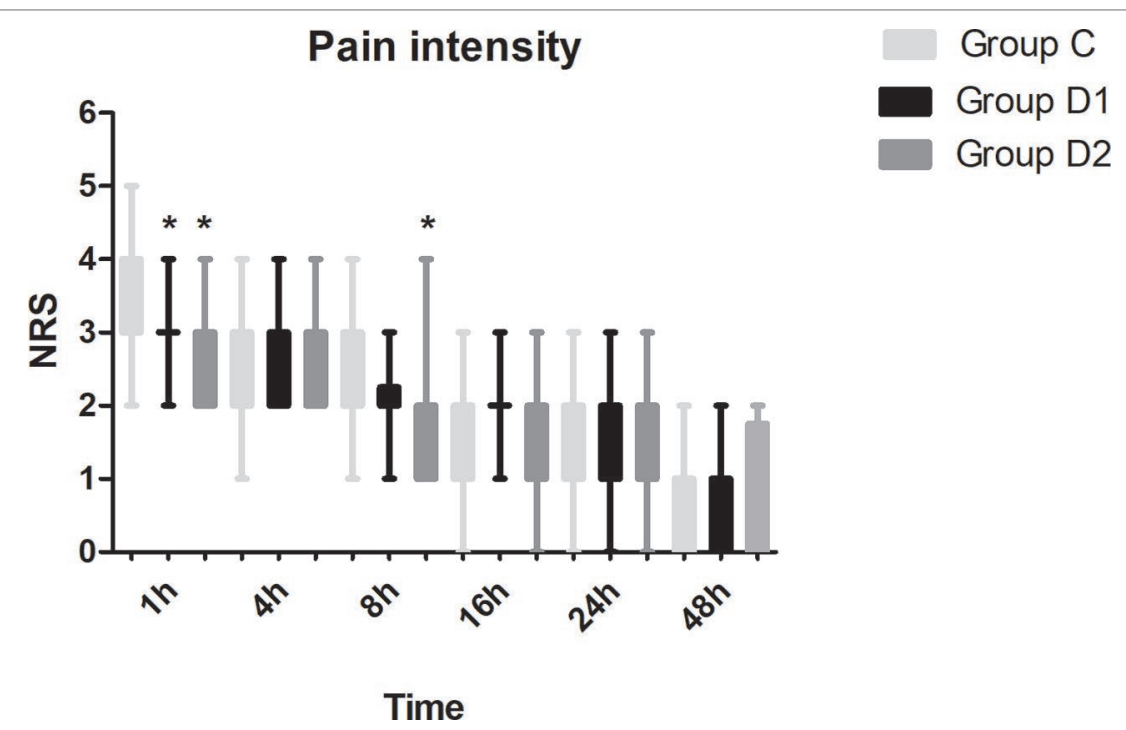

FIGURE 5 | Postoperative pain intensity in the three groups expressed as scores on a numerical rating scale (NRS) out of $10 .{ }^{*} P<0.05$ vs. group C.

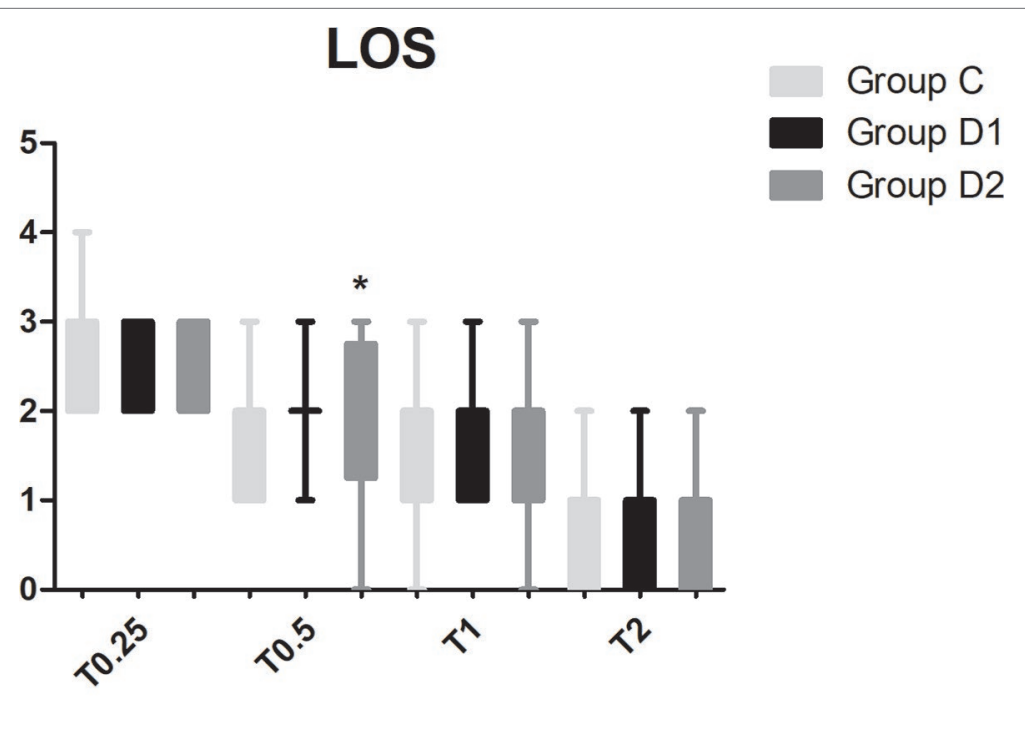

Time

FIGURE 6 | Comparison of patient sedation among the three groups using the level of sedation (LOS). LOS: 1, the subject is anxious, agitated, or restless; 2 , the subject is cooperative, oriented, tranquil, and responds to commands; 3 , the subject is asleep but has a brisk response to light glabellar tap or a loud auditory stimulus; 4, the subject is asleep, has a sluggish response to a light glabellar tap or loud auditory stimulus; 5 , the subject is asleep and unresponsive. ${ }^{*} P<0.05$ vs. group C.

Hence, the author proposed that administration of a plasma expanding drug could be an appropriate strategy to reduce the risk of sudden initial BP reactions (Niaz and Nayyar, 2003). We also monitored the hemodynamic changes $48 \mathrm{~h}$ after surgery as Heiss found that the BP change in the first 2 days after surgery was sufficient for analysis of neurological and functional outcome (Heiss, 2017). Only one patient in group D2 had hypotension in this trial, and the differences among the three groups did not reach statistical significance. The incidence of hypotension in group D2 was lower than that of the previous study, which may be attributed to the lower consumption of nimodipine and the synergistic effects of nimodipine and dexmedetomidine (Konczalla et al., 2016). Dexmedetomidine, a new highly selective agonist of $\alpha 2$ adrenergic receptor, is widely used in neurosurgery such as craniotomy, CEA for sedation, analgesia, and low risk of respiratory depression. A recent study reported that dexmedetomidine produced neuroprotective effects although the specific mechanism is still not known (Perez-Zoghbi et al., 2017). However, we did not observe this phenomenon possibly due to the lower dose of dexmedetomidine used in this trial.

Since 1991, an increasing number of patients choose intravascular embolization to treat aSAH. Compared with surgical clipping, both 


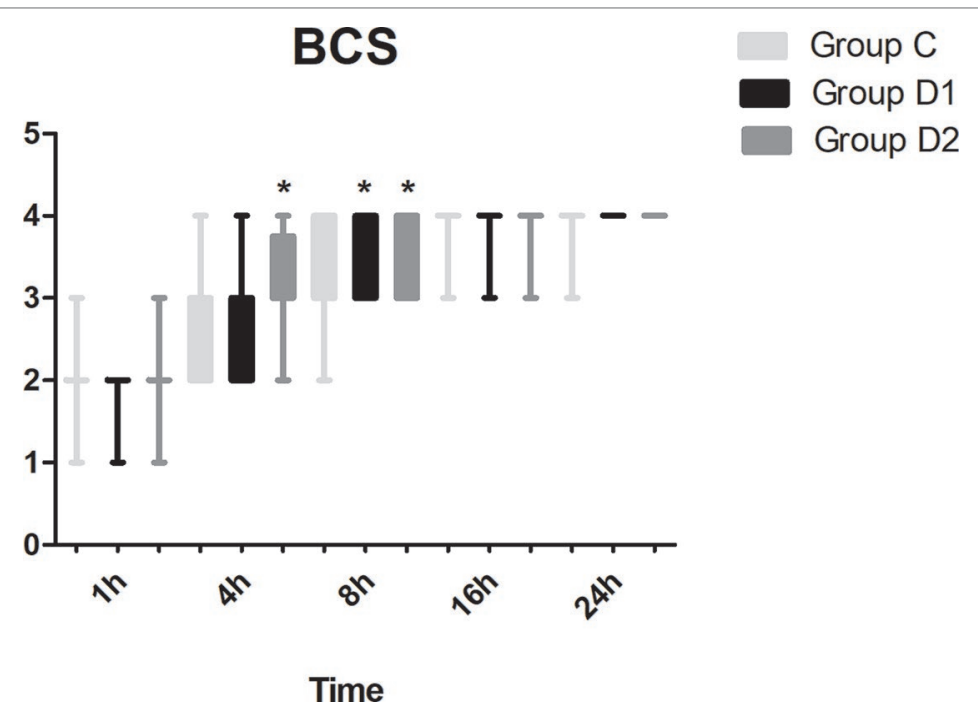

FIGURE 7 | Comparison of Bruggemann Comfort Scale (BCS) scores among the three groups. BCS: 0, persistent pain; 1, severe pain while deep breathing or coughing; 2 , mild pain while deep breathing or coughing; 3 , painless while deep breathing; 4 , painless while coughing. ${ }^{\star} P<0.05$ vs. group $C$.

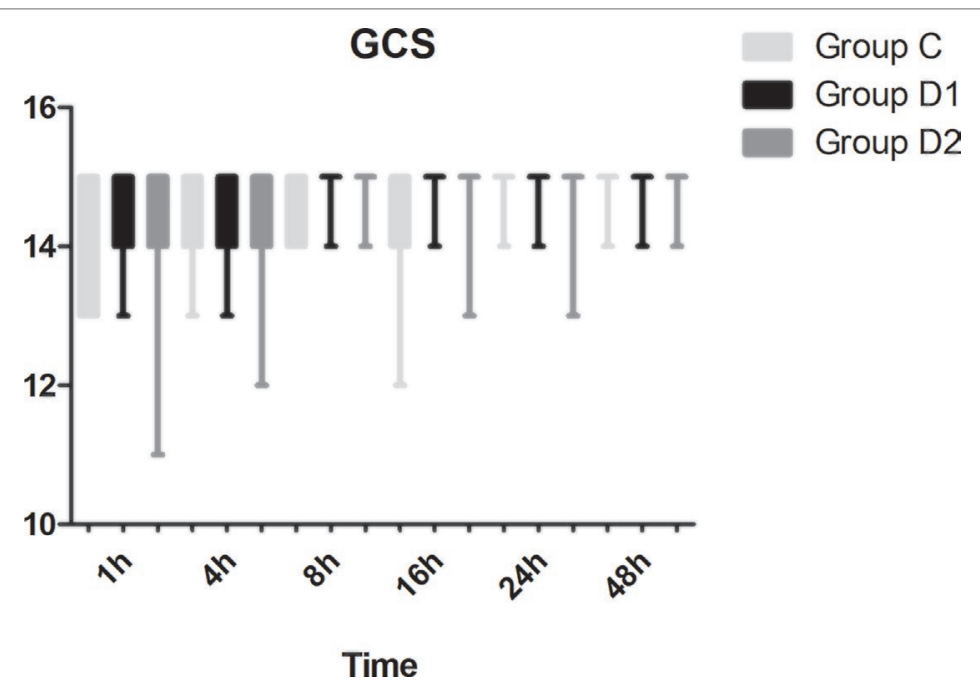

FIGURE 8 | Comparison of the Glasgow Coma Scale (GCS) scores among the three groups.

TABLE 6 | Postoperative adverse effects of patients in the three groups.

\begin{tabular}{|c|c|c|c|c|}
\hline Variable & Group C ( $n=35)$ & Group D1 $(n=38)$ & Group D2 $(n=36)$ & $P$-values \\
\hline Nausea & 4 (11.43\%) & 4 (10.53\%) & 3 (8.33\%) & .926 \\
\hline Dizzy & 5 (14.29\%) & $2(5.26 \%)$ & 3 (8.33\%) & .376 \\
\hline Thirst & - & - & $3(8.33 \%)$ & .065 \\
\hline Hypertension & 7 (20.00\%) & 5 (13.16\%) & $4(11.11 \%)$ & .556 \\
\hline Hypotension & $3(8.57 \%)$ & $4(10.53 \%)$ & $1(2.78 \%)$ & .480 \\
\hline
\end{tabular}

Variables presented as number of patients $n(\%)$.

short- and long-term morbidity and mortality rates are reduced in patients treated with endovascular coiling (Tamargo et al., 2001). We recruited patients who were admitted to our hospital within $72 \mathrm{~h}$ of the initial hemorrhage event since decreased in-hospital mortality may be associated with early aneurysm treatment. Intraprocedural aneurysm rupture during endovascular coiling may lead to rapid increase in intracranial pressure. Hyperventilation and osmotic diuresis are the routinely used methods to control intracranial hypertension. In this trial, MAP was maintained at $\pm 20 \%$ of baseline to avoid ischemia. In patients with intact autoregulation, administration of norepinephrine and epinephrine was found to be more suitable to maintain cerebral perfusion pressure compared 
with dopamine (Sookplung et al., 2011). Raabe et al. reported that moderate hypertension induced by phenylephrine may improve brain tissue oxygen pressure values (Raabe et al., 2005). Hence, we adopted phenylephrine and ephedrine to address hypotension in this trial.

Additionally, McNeill showed that the 6-month mortality of $\mathrm{SAH}$ is inversely related to the treatment institution. Highvolume hospitals ( $>60$ cases per year) improve the outcomes of patients by provision of neurocritical care units (McNeill, 2007). In our hospital, more than 400 patients undergo endovascular treatment every year and many specialized multidisciplinary teams have been established since 2012, which includes specialized NICU nurses, vascular neurosurgeons, interventional neuroradiologists, neuroanesthesiologist, and neurointensivists. Hence, the percentage of favorable outcomes in our hospital is about $40 \%$, which is closer to the global levels. Hypernatremia, hyponatremia, and elevated blood glucose concentration are frequent complications in the acute phase after aSAH (Priebe, 2007). In our trial, the electrolyte level at $48 \mathrm{~h}$ after surgery was within normal limits because we recruited good-grade patients.

There are several limitations in this trial. First, the number of patients included in this trial is small and hence these results need to be confirmed by larger multicenter randomized controlled trials. Second, we did not measure the serum concentration of dexmedetomidine in this trial as a result of high hospital costs. Third, this trial only studied one dosage of dexmedetomidinesufentanil after neurosurgery; different dosages should be further investigated. Finally, further studies on specific clinical monitoring for SAH patients are needed, especially for poor-grade patients.

In summary, we report for the first time, that high dose of dexmedetomidine (infusion at $0.5 \mu \mathrm{g} \cdot \mathrm{kg}^{-1}$ for $10 \mathrm{~min}$, then adjusted to $0.4 \mu \mathrm{g} \cdot \mathrm{kg}^{-1} \cdot \mathrm{h}^{-1}$ during surgery) significantly reduced the total

\section{REFERENCES}

Abboud, T., Andresen, H., Koeppen, J., Czorlich, P., Duehrsen, L., Stenzig, J., et al. (2015). Serum levels of nimodipine in enteral and parenteral administration in patients with aneurysmal subarachnoid hemorrhage. Acta Neurochir. (Wien). 157 (5), 763-767. doi: 10.1007/s00701-015-2369-9

Adami, D., Berkefeld, J., Platz, J., Konczalla, J., Pfeilschifter, W., Weidauer, S., et al. (2019). Complication rate of intraarterial treatment of severe cerebral vasospasm after subarachnoid hemorrhage with nimodipine and percutaneous transluminal balloon angioplasty: worth the risk? J. Neuroradiol. 46 (1), 15-24. doi: 10.1016/j.neurad.2018.04.001

Ahmed, N., Näsman, P., and Wahlgren, N. G. (2000). Effect of intravenous nimodipine on blood pressure and outcome after acute stroke. Stroke 31 (6), 1250-1255. doi: 10.1161/01.STR.31.6.1250

Alam, A., Suen, K. C., Hana, Z., Sanders, R. D., Maze, M., and Ma, D. (2017). Neuroprotection and neurotoxicity in the developing brain: an update on the effects of dexmedetomidine and xenon. Neurotoxicol. Teratol. 60, 102-116. doi: 10.1016/j.ntt.2017.01.001

Bacigaluppi, S., Zona, G., Secci, F., Spena, G., Mavilio, N., Brusa G., et al. (2015). Diagnosis of cerebral vasospasm and risk of delayed cerebral ischemia related to aneurysmal subarachnoid haemorrhage: an overview of available tools. Neurosurg. Rev. 38 (4), 603-618. doi: 10.1007/s10143-015-0617-3

Boulouis, G., Labeyrie, M. A., Raymond, J., Rodriguez-Régent, C., Lukaszewicz, A. C., Bresson, D., et al. (2017). Treatment of cerebral vasospasm following aneurysmal subarachnoid haemorrhage: a systematic review and meta-analysis. Eur. Radiol. 27 (8), 3333-3342. doi: 10.1007/ s00330-016-4702-y consumption of nimodipine during the first $48 \mathrm{~h}$ after surgery and promoted early rehabilitation of patients although the incidence of symptomatic cerebral vasospasm, GOS, and cerebral infarction were not reduced. However, more multi-center prospective studies are required to determine the optimal dosage of dexmedetomidine during the perioperative period of neurosurgery.

\section{DATA AVAILABILITY}

All datasets generated for this study are included in the manuscript and the supplementary files.

\section{ETHICS STATEMENT}

All procedures performed in studies involving human participants were in accordance with the ethical standards of the institutional and/ or national research committee and with the 1964 Helsinki declaration and its later amendments or comparable ethical standards.

\section{AUTHOR CONTRIBUTIONS}

CR, JG, GX, LZ, JC and ZZ conceived and designed the trial; JG and $\mathrm{HX}$ analyzed the data; CR, GL and LL collected the data, CR, JG, GX, HX, ZZ wrote this paper. JC and ZZ contributed equally to and should be considered co-corresponding author.

\section{FUNDING}

This work was supported by the Natural Science Foundation of Shandong Province (ZR2016HB28).

Bricout, N., Estrade, L., Boustia, F., Kalsoum, E., Pruvo, J. P., Leclerc, X., et al (2015). Reduced-dose CT protocol for the assessment of cerebral vasospasm. Neuroradiology 57 (12), 1211-1218. doi: 10.1007/s00234-015-1585-6

Casey, G., Nortcliffe, S. A., Sharpe, P., and Buggy, D. J., (2006). Perioperative nimodipine and postoperative analgesia. Anesth. Analg. 102 (2), 504-508. doi: 10.1213/01.ane.0000194448.37407.6a

Chhor, V., Le Manach, Y., Clarençon, F., Nouet, A., Daban, J. L., Abdennour L., et al. (2011). Admission risk factors for cerebral vasospasm in ruptured brain arteriovenous malformations: an observational study. Crit. Care 15 (4), R190. doi: $10.1186 /$ cc10345

Ciporen, J., Gillham, H., Noles, M., Dillman, D., Baskerville, M., Haley, C., et al. (2018). Crisis management simulation: establishing a dual neurosurgery and anesthesia training experience. J. Neurosurg. Anesthesiol. 30 (1), 65-70. doi: 10.1097/ANA.0000000000000401

Connolly, E. S., Jr, Rabinstein, A. A., Carhuapoma, J. R., Derdeyn, C. P., Dion, J., Higashida R. T., et al. (2012). Guidelines for the management of aneurysmal subarachnoid hemorrhage: a guideline for healthcare professionals from the American Heart Association/American Stroke Association. Stroke 43 (6), 1711-1737. doi: 10.1161/STR.0b013e3182587839

Duan, X., Coburn, M., Rossaint, R., Sanders, R. D., Waesberghe, J. V., Kowark, A., et al. (2018). Efficacy of perioperative perioperative dexmedetomidine on postoperative delirium: systematic review and meta-analysis with trial sequential analysis of randomised controlled trials. Br. J. Anaesth. 121 (2), 384-397. doi: 10.1016/j.bja.2018.04.046

Fan, C. H., Peng, B., and Zhang, F. C. (2017). Influence of laryngeal mask airway (LMA) insertion anesthesia on cognitive function after microsurgery in pediatric neurosurgery. Eur Rev. Med. Pharmacol. Sci. 21 (4 Suppl), 37-42. 
Francoeur, C. L., and Mayer, S. A. (2016). Management of delayed cerebral ischemia after subarachnoid hemorrhage. Crit. Care 20 (1), 277. doi: 10.1186/ s13054-016-1447-6

Garavaglia, M. M., Das, S., Cusimano, M. D., Crescini, C., Mazer, C. D., Hare, G. M., et al. (2014). Anesthetic approach to high-risk patients and prolonged awake craniotomy using dexmedetomidine and scalp block. J. Neurosurg Anesthesiol. 26 (3), 226-233. doi: 10.1097/ANA.0b013e3182a58aba

Hänggi, D., Etminan, N., Macdonald, R. L., Steiger, H. J., Mayer, S. A., Aldrich, F., et al. (2015). NEWTON: nimodipine microparticles to enhance recovery while reducing toxicity after subarachnoid hemorrhage. Neurocrit. Care 23 (2), 274284. doi: 10.1007/s12028-015-0112-2

Heiss, W. D. (2017). Contribution of neuro-imaging for prediction of functional recovery after ischemic stroke. Cerebrovasc. Dis. 44 (5-6), 266-276. doi: $10.1159 / 000479594$

Hughes, J. D., Bond, K. M., Mekary, R. A., Dewan, M. C., Rattani, A., Baticulon, R., et al. (2018). Estimating the global incidence of aneurysmal subarachnoid hemorrhage: a systematic review for central nervous system vascular lesions and meta-analysis of ruptured aneurysms. World Neurosurg. 115, 430-447. doi: 10.1016/j.wneu.2018.03.220

Jung, S. W., Lee, C. Y., and Yim, M. B. (2012). The relationship between subarachnoid hemorrhage volume and development of cerebral vasospasm. J. Cerebrovasc. Endovasc. Neurosurg. 14 (3), 186-191. doi: 10.7461/jcen.2012.14.3.186

Kellner, P., Stoevesandt, D., Soukup, J., Bucher, M., Raspé, C., et al. (2012). Aneurysmal subarachnoid hemorrhage. Anaesthesist. 61 (9), 792-814. doi: 10.1007/s00101-12-2077-2

Kieninger, M., Flessa, J., Lindenberg, N., Bele, S., Redel, A., Schneiker, A., et al. (2018). Side effects of long-term continuous intra-arterial nimodipine infusion in patients with severe refractory cerebral vasospasm after subarachnoid hemorrhage. Neurocrit. Care 28 (1), 65-76. doi: 10.1007/s12028-017-0428-1

Konczalla, J., Kashefiolasl, S., Brawanski, N., Lescher, S., Senft, C., Platz, J., et al. (2016). Cerebral vasospasm and delayed cerebral infarctions in 225 patients with non-aneurysmal subarachnoid hemorrhage: the underestimated risk of Fisher 3 blood distribution. J. Neurointerv. Surg. 8 (12), 1247-1252. doi: 10.1136/neurintsurg-2015-012153

Lawton, M. T., and Vates, G. E. (2017). Subarachnoid hemorrhage. N. Engl. J. Med. 377 (3), 257-266. doi: 10.1056/NEJMcp1605827

Lindgren, A., Vergouwen, M. D., van der Schaaf, I., Algra, A., Wermer, M., Clarke, M. J., et al. (2018). Endovascular coiling versus neurosurgical clipping for people with aneurysmal subarachnoid haemorrhage. Cochrane Database Syst. Rev. 8, CD003085. doi: 10.1002/14651858.CD003085.pub3

McCutcheon, C. A., Orme, R. M., Scott, D. A., Davies, M. J., McGlade, D. P., et al. (2006). A comparison of dexmedetomidine versus conventional therapy for sedation and hemodynamic control during carotid endarterectomy performed under regional anesthesia. Anesth. Analg. 102 (3), 668-675. doi: 10.1213/01.ane.0000197777.62397.d5

McNeill, A. (2007). Neurological negligence claims in the NHS from 1995 to 2005. Eur. J. Neurol. 14 (4), 399-402. doi: 10.1111/j.1468-1331.2007.01677.x

Niaz, A., and Nayyar, S. (2003). Cerebrovascular stroke at high altitude. J. Coll. Physicians Surg. Pak. 13 (8), 446-448.

Oertel, M., Boscardin, W. J., Obrist, W. D., Glenn, T. C., McArthur, D. L., Gravori, T., et al. (2005). Posttraumatic vasospasm: the epidemiology, severity, and time course of an underestimated phenomenon: a prospective study performed in 299 patients. J. Neurosurg. 103 (5), 812-824. doi: 10.3171/jns.2005.103.5.0812

Perez-Zoghbi, J. F., Zhu, W., Grafe, M. R., Brambrink, A. M., et al. (2017). Dexmedetomidine-mediated neuroprotection against sevoflurane-induced neurotoxicity extends to several brain regions in neonatal rats. Br. J. Anaesth. 119 (3), 506-516. doi: 10.1093/bja/aex222

Prabhakar, H., Mahajan, C., and Kapoor, I. (2017). Anesthesia for minimally invasive neurosurgery. Curr. Opin. Anaesthesiol. 30 (5), 546-550. doi: 10.1097/ ACO.0000000000000499

Priebe, H. J. (2007). Aneurysmal subarachnoid haemorrhage and the anaesthetist. Br. J. Anaesth. 99 (1), 102-118. doi: 10.1093/bja/aem119

Raabe, A., Beck, J., Keller, M., Vatter, H., Zimmermann, M., Seifert, V. et al. (2005). Relative importance of hypertension compared with hypervolemia for increasing cerebraloxygenation in patients with cerebral vasospasm after subarachnoid hemorrhage. J. Neurosurg. 103 (6), 974-981. doi: 10.3171/ jns.2005.103.6.0974

Rao, G. S., and Muthuchellappan, R. (2016). Cerebral vasospasm: current understanding. Curr. Opin. Anaesthesiol. 29 (5), 544-551. doi: 10.1097/ ACO.0000000000000370

Sanelli, P. C., Pandya, A., Segal, A. Z., Gupta, A., Hurtado-Rua, S., Ivanidze, J., et al. (2014). Cost-effectiveness of CT angiography and perfusion imaging for delayed cerebral ischemia and vasospasm in aneurysmal subarachnoid hemorrhage. AJNR Am. J. Neuroradiol. 35 (9), 1714-1720. doi: 10.3174/ajnr.A3947

Scheller, C., Wienke, A., Tatagiba, M., Gharabaghi, A., Ramina, K. F., Ganslandt, O., et al. (2016). Prophylactic nimodipine treatment for cochlear and facial nerve preservation after vestibular schwannoma surgery: a randomized multicenter Phase III trial. J. Neurosurg. 124 (3), 657-664. doi: 10.3171/2015.1.JNS142001

Shimamura, N., and Ohkuma, H. (2014). Phenotypic transformation of smooth muscle in vasospasm after aneurysmal subarachnoid hemorrhage. Transl. Stroke Res. 5 (3), 357-364. doi: 10.1007/s12975-013-0310-1

Sookplung., P., Siriussawakul, A., Malakouti, A., Sharma, D., Wang, J., Souter, M. J. (2011). Vasopressor use and effect on blood pressure after severe adult traumatic brain injury. Neurocrit. Care 15 (1), 46-54. doi: 10.1007/s12028-010-9448-9

Soppi, V., Kokki, H., Koivisto, T., Lehtonen, M., Helin-Tanninen, M., Lehtola, S., et al. (2007). Early-phase pharmacokinetics of enteral and parenteral nimodipine in patients with acute subarachnoid haemorrhage - a pilot study. Eur. J. Clin. Pharmacol. 63 (4), 355-361. doi: 10.1007/s00228-007-0267-7

Soppi, V., Karamanakos, P. N., Koivisto, T., Kurki, M. I., Vanninen, R., Jaaskelainen, J. E., et al. (2012). A randomized outcome study of enteral versus intravenous nimodipine in 171 patients after acute aneurysmal subarachnoid hemorrhage. World Neurosurg. 78 (1-2), 101-109. doi: 10.1016/j.wneu.2011.09.030

Su, S., Ren, C., Zhang, H., Liu, Z., and Zhang, Z., (2016). The opioid-sparing effect of perioperative dexmedetomidine plus sufentanil infusion during neurosurgery: a retrospective study. Front Pharmacol. 7, 407. doi: 10.3389/fphar.2016.00407

Tallarico, R. T., Pizzi, M. A., and Freeman, W. D. (2018). Investigational drugs for vasospasm after subarachnoid hemorrhage. Expert Opin. Investig. Drugs 27 (4), 313-324. doi: 10.1080/13543784.2018.1460353

Tamargo, R. J., Rigamonti, D., Murphy, K., Gailloud, P., Conway, J. E., Clatterbuck, R. E., et al. (2001). Treatment of intracranial aneurysms: surgical clipping or endovascular coiling? Ann. Neurol. 49 (5), 682-684. doi: 10.1002/ana.1041

Tjahjadi, M., König, R., Wirtz, C. R., Woischneck, D., and Kapapa, T., et al. (2013). Cerebral vasospasm and health-related quality of life after subarachnoid hemorrhage. World Neurosurg. 80 (1-2), 113-120. doi: 10.1016/j.wneu.2012. 09.011

Wong, G. K., Lee, A., Wong, A., Ho, F. L., Leung, S. L., Zee, B. C., et al. (2016). Clinically important difference of Stroke-Specific Quality of Life Scale for aneurysmal subarachnoid hemorrhage. J. Clin Neurosci. 33, 209-212. doi: 10.1016/j.jocn.2016.05.029

Zarauza, R., Sáez-Fernández, A. N., Iribarren, M. J., Carrascosa, F., Adame, M., Fidalgo, I., et al. (2000). A comparative study with oral nifedipine, intravenous nimodipine, and magnesium sulfate in postoperative analgesia. Anesth. Analg. 91 (4), 938-943. doi: 10.1097/00000539-200010000-00032

Zwienenberg-Lee, M., Hartman, J., Rudisill, N., Madden, L. K., Smith, K., Eskridge, J., et al. (2008). Effect of prophylactic transluminal balloon angioplasty on cerebral vasospasm and outcome in patients with Fisher grade III subarachnoid hemorrhage: results of a phase II multicenter, randomized, clinical trial. Stroke 39 (6), 1759-1765. doi: 10.1161/STROKEAHA.107.502666

Conflict of Interest Statement: The authors declare that the research was conducted in the absence of any commercial or financial relationships that could be construed as a potential conflict of interest.

Copyright (c) 2019 Ren, Gao, Xu, Xu, Liu, Liu, Zhang, Cao and Zhang. This is an open-access article distributed under the terms of the Creative Commons Attribution License (CC BY). The use, distribution or reproduction in other forums is permitted, provided the original author(s) and the copyright owner(s) are credited and that the original publication in this journal is cited, in accordance with accepted academic practice. No use, distribution or reproduction is permitted which does not comply with these terms. 